\section{Endoscopic ultrasound and fine needle aspiration for the diagnosis of extragonadal seminoma metastatic to the pancreas}

A 35-year man presented with back pain and paraparesis. Computed tomography of the abdomen and chest showed a pancreatic mass and a spinal canal lesion from L5 to S3. Of note, a year earlier, he had been in a motor vehicle accident, at which time emergency computed tomography of the chest showed a mediastinal tumor. Tissue obtained during thoracoscopy demonstrated a granulomatous tissue reaction.

During the present admission, the patient underwent an endoscopic ultrasound (EUS) examination because pancreatic cancer metastatic to the spine was suspected. EUS showed a hypoechoic, infiltrative $2.5-\mathrm{cm}$ lesion in the body of the pancreas. The lesion infiltrated the surrounding tissue and was close to the splenic vein and celiac artery, but without signs of invasion. EUS-guided fine needle aspiration with a 22-gauge needle (Boston Scientific, MA, USA) was used to obtain a specimen. Cytology showed granulomas and a few isolated, large malignant cells, each with a round nucleus, visible nucleoli, and a moderate amount of finely vacuolated cytoplasm ( $\bullet$ Fig. 1, Fig.2). The cytologic differential diagnosis included seminoma and large cell lymphoma. Immunocytochemistry was not done. We also obtained a biopsy specimen of the vertebral lesion, which confirmed the diagnosis of seminoma. Both testes were negative for tumor mass, so we suspected that seminoma had already been present in the mediastinum a year earlier. The patient was referred for oncologic therapy. This case is interesting because it shows an unusual metastasis of a nongonadal seminoma to the pancreas. Whereas tu- mors such as those of the breast, kidney, and lung often metastasize to the pancreas, it is extremely uncommon for a seminoma to present as a pancreatic lesion $[1,2]$. This case is of additional interest because it demonstrates the utility of cytology to establish a diagnosis. Our case and the case reported by Wehrschütz et al. underscore the importance of cytohistopathologic examination [3]. Lastly, these unique cytologic images may be useful to illustrate the characteristics of metastatic seminoma.

Endoscopy_UCTN_Code_CCL_1AF_2AZ_3AB

\section{Competing interests: None}

\section{Tajana Stoos-Veic ${ }^{1}$, Mario Tadic ${ }^{2}$}

${ }^{1}$ Department of Pathology and Cytology, Dubrava University Hospital

${ }^{2}$ Department of Gastroenterology, Dubrava University Hospital, Zagreb, Croatia

\section{References}

1 Gnemmi V, Leroy X, Triboulet JP et al. Pancreatic metastases of renal clear cell carcinoma: a clinicopathological study of 11 cases with special emphasis on the usefulness of PAX2 and mesothelin for the distinction from primary ductal adenocarcinoma of the pancreas. Anal Quant Cytol Histol 2013; 35: 157-162

2 Olson MT, Wakely PE Jr, Ali SZ. Metastases to the pancreas diagnosed by fine-needle aspiration. Acta Cytol 2013; 57: 473-480

3 Wehrschütz M, Stöger H, Ploner F et al. Seminoma metastases mimicking primary pancreatic cancer. Onkologie 2002; 25: 371 373

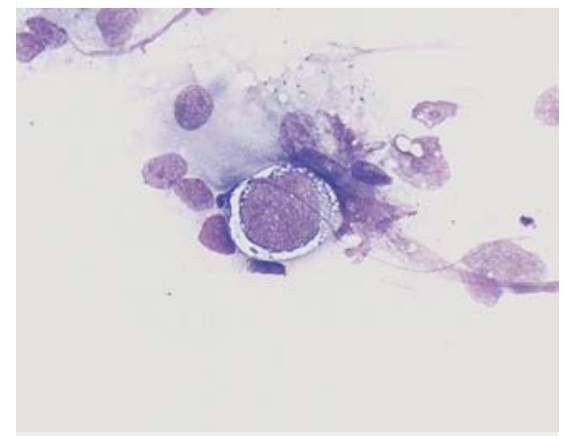

Fig. 1 Extragonadal seminoma metastatic to the pancreas. An isolated malignant cell has a round nucleus, visible nucleoli, and a moderate amount of finely vacuolated cytoplasm. A few histiocytes are seen in the background (MayGrünwald-Giemsa stain, original magnification $\times 1000$ ).

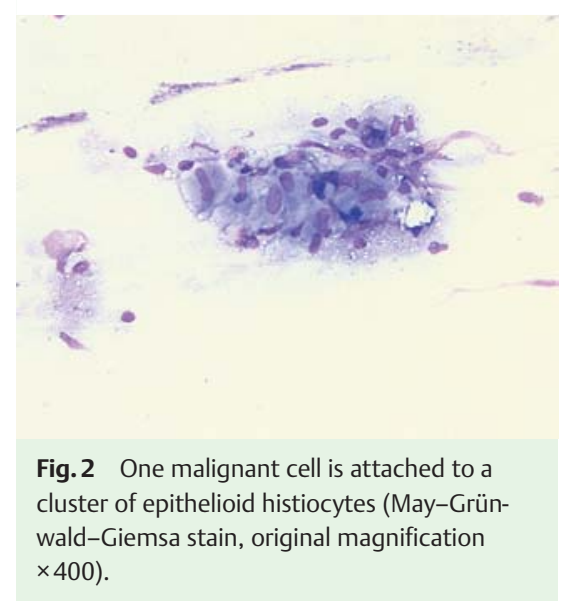

Bibliography

Dol http://dx.doi.org/

10.1055/s-0034-1377596

Endoscopy 2014; 46: E522

(c) Georg Thieme Verlag KG

Stuttgart · New York

ISSN 0013-726X

\section{Corresponding author}

\section{Tajana Stoos-Veic, MD, PhD}

Department of Pathology and Cytology

Dubrava University Hospital

Av. Gojka Suska 6

10040 Zagreb

Croatia

Fax: 385-1-290-2554

tajanaveic@gmail.com 